\title{
Avaliação da orientação para a aprendizagem: Um estudo de caso na empresa Supertex de Santa Maria/RS
}

\author{
Evaluation of learning orientation: A case study in Supertex company of Santa \\ Maria/RS
}

\author{
Eduardo Botti Abbade \\ UNIFRA \\ e-mail: eduardo@unifra.br \\ Tassiana Pivetta Vizzotto \\ Bacharel em Administração \\ Greice de Bem Noro \\ Professora da UNIFRA
}

Artigo Recebido em 19.07.2011. Revisado por pares em 12.11.2011. Recomendado em 12.11.2011 por Edson Roberto Scharf, Editor Responsável. Publicado em 30.06.2012. Organização responsável pelo periódico: FURB Universidade de Blumenau (www.furb.br/rn)

\begin{abstract}
Resumo
O tema Aprendizagem Organizacional tem despertado interesse nos últimos anos no meio acadêmico. Tendo em vista este fato, este estudo tem como objetivo analisar a atual postura de orientação para a aprendizagem de uma empresa atuante no comércio de concreto de Santa MariaRS. Para tanto, adotou-se a escala proposta por Sinkula, Baker, e Noordewier (1997) para descrever a situação atual de Orientação para a Aprendizagem da empresa estudada. Um instrumento de coleta de dados composto pelos 18 itens foi aplicado a 38 gestores do setor administrativo da empresa. Como resultado verificou-se que a empresa possui uma orientação para a aprendizagem satisfatória. Entretanto apresentou resultados interessantes de diferenças de percepção entre grupos de sexos distintos assim como correlação significativa entre aspectos de visão compartilhada e tempo de empresa e tempo de caro. Assim, sugerem-se estudos futuros que visem identificar possíveis divergências de percepções quanto a Aprendizagem Organizacional em níveis organizacionais e áreas funcionais distintas.
\end{abstract}

Palavras-chaves: Vantagem Competitiva; Aprendizagem Organizacional; Estratégia.
Abstract
The organizational learning theme has attracted attention in academia at last years. Given this fact, this study aims to analyze the current posture of learning orientation of a company that act in the trade of concrete in Santa Maria-RS. To accomplish this goal, it was adopted the scale proposed by Sinkula, Baker, and Noordewier (1997) to describe the current situation of Learning Orientation of the studied company. An instrument of data collection consisting of 18 items was applied to 38 managers in the administrative sector of the company. As results, it was found that the company has a satisfactory learning orientation. However results showed interesting differences in perception between groups of different sexes as well as significant correlation between aspects of shared vision and permanence time of respondents in the company. Thus, it is suggested future studies aimed at identifying possible differences in 
perceptions about organizational learning and organizational levels in different functional areas.

Key-words: Competitive Advantage; Organizational Learning; Strategy.

\section{Introdução}

A atual conjuntura competitiva em que as organizações estão inseridas é considerada altamente turbulenta e exige respostas inovadoras e adaptativas constantemente. Tendo em vista esta exigência do mercado, a gestão do conhecimento e a aprendizagem organizacional têm despertado a atenção de estudiosos e gestores organizacionais nos últimos anos, pois o fenômeno da aprendizagem possibilita melhores condições de resposta às organizações desde que gerenciada de modo eficiente e eficaz.

O aprendizado pode ser definido como o processo de decodificar, reter e usar a informação disponível (HOWELL e COOKE, 1989). Assim, a gestão do conhecimento baseada na aprendizagem organizacional não se encarrega únicamente de criar um repositório de informações, mas busca estruturar a organização em termos disseminando uma filosofia de trabalho voltada para o conhecimento. Esta pratica estruturada justifica-se pela constatação de que a implantação coordenada da Gestão do Conhecimento pode vir a criar vantagem competitiva sustentável e de difícil imitação (BARNEY, 1991), pois está sedimentada nas pessoas que atuam na organização, e não em ativos físicos, que podem ser facilmente imitados pelos concorrentes (QUINN et al, 1997) e mais específicos e menos flexíveis para reagir às incertezas do ambiente e alterações transacionais (THOMKE REINERTSEN, 1998; WILLIAMSON, 1985).

A disponibilidade de informações sobre o mundo, a economia, a sociedade, a ciência, a tecnologia, a arte e a tudo mais, que seja interessante ou não, útil ou fútil, é ampla e está em todos os lugares ao mesmo tempo. As pessoas, nestes tempos, são bombardeadas por uma série de acontecimentos. Portanto, a informação em si, pertence a todos, até os que por ela não buscam, impreterivelmente em algum momento, estão mergulhados pelos meios que a propagam. No entanto, é preciso capacidade de retê-la e tornar isso um benefício para si e para os outros, de transformá-la em conhecimento e inovação (BRESCIANI, 1999).

De acordo com esta realidade relativa à necessidade de uma orientação organizacional para a aprendizagem e gestão do conhecimento este estudo foi conduzido. Assim, este estudo tem como objetivo analisar a atual postura de orientação para a aprendizagem de uma empresa atuante no comércio de concreto de Santa Maria-RS. Como objetivos específicos este estudo visa (1) caracterizar a natureza da empresa estudada; (2) analisar o perfil dos dirigentes da empresa; (3) descrever a atual orientação para a aprendizagem vigente; e (4) identificar as deficiências e fragilidades da orientação para a aprendizagem.

Assim, este estudo se caracteriza por ser um diagnóstico a respeito da atual situação da empresa estudada gerando assim condições de identificação de pontos a serem melhorados. Também este estudo justifica-se por consolidar um tema teórico-científico de grande importância no meio acadêmico e que tem adquirido interesse de pesquisadores. A adoção da escala de mensuração proposta por Sinkula, Baker, e Noordewier (1997) é uma maneira de buscar consolidar a mesma como uma ferramenta de diagnóstico gerencial que possa auxiliar os tomadores de decisões estratégicas.

\section{Gestão da aprendizagem e do conhecimento}


Eboli (2004) coloca o conhecimento como fonte de vantagem competitiva para as empresas que visam um desenvolvimento sustentável. Gerar e transferir conhecimento na empresa são processos de aprendizagem organizacional. Considera-se o conhecimento como conexão e não como coleção. Mais importante do que gerar novos conhecimentos é fazer conexões com conhecimentos já existentes, ampliando a rede de relacionamentos internos e externos da organização

Independentemente da estratégia adotada, atualmente o gerenciamento efetivo do conhecimento corporativo torna-se capaz de garantir à empresa o diferencial competitivo capaz de levá-la à uma posição de liderança. Surge então a gestão estratégica do conhecimento corporativo, definido como a tarefa de identificar, desenvolver, disseminar e atualizar o conteúdo estrategicamente relevante para a empresa, por meio de processos internos ou externos, (FLEURY e OLIVEIRA, 2001).

Seu processo de implantação nas empresas pressupõe uma mudança cultural, visando ao comprometimento de toda a organização. Quanto mais informações disponíveis para a obtenção e disseminação do conhecimento, além da gestão sobre o conhecimento, maior será o poder de tomada de decisão na empresa, gerando benefícios substanciais em termos de produtividade, lucratividade e competitividade.

Nonaka e Takeuchi (1997), inspirados em Platão, consideram o conhecimento como um processo humano dinâmico de justificar a crença pessoal com relação à verdade. Já para Crawford (1994) conhecimento é a capacidade de aplicar a informação a um trabalho ou a um resultado específico.

A gestão do conhecimento enfoca principalmente aqueles aspectos críticos para a adaptação e sobrevivência da em- presa, diante de uma realidade ou cenário econômico mutável e descontínuo. Nas empresas que aprendem, que são inovadoras, o conhecimento coletivo compartilhado já é reconhecido como uma competência fundamental para a performance organizacional, baseando-se nas habilidades e experiências individuais no trabalho realizado. Essas empresas utilizam processos de criação de um ambiente organizacional, buscando uma sinergia entre valores individuais e valores de grupo, tendendo a um nivelamento do conhecimento entre os membros da organização (BUENO et al, 2004).

Nas organizações, a criação do conhecimento ocorre através da interação contínua entre os conhecimentos tácito e explícito. Para criar conhecimento, é preciso envolver os trabalhadores de tal forma que todos se sintam comprometidos com o mesmo, "a invenção de novos conhecimentos não é atividade especializada, província exclusiva das áreas de $\mathrm{P} \& \mathrm{D}$, marketing ou planejamento estratégico (NONAKA e TAKEUCHI, 1997, p. 31). Além disso, a empresa precisa estimular a integração de todos os indivíduos rumo às novas aplicações do conhecimento que já está disponível em sua estrutura.

Acredita-se que os seres humanos adquirem conhecimentos criando e organizando ativamente suas próprias experiências. $\mathrm{O}$ conhecimento que pode ser expresso em palavras representa apenas uma pequena parte do todo. Podemos saber mais do que podemos dizer (NONAKA e TAKEUCHI, 1997, p. 65). Ainda salientam-se dois tipos de conhecimentos, citados no quadro 01 .

Quadro 01 - Conhecimento Tácito e Conhecimento Explícito

\begin{tabular}{|c|c|}
\hline $\begin{array}{c}\text { Conhecimento Tácito } \\
\text { (Subjetivo) }\end{array}$ & $\begin{array}{c}\text { Conhecimento } \\
\text { Explícito (Objetivo) }\end{array}$ \\
\hline
\end{tabular}




\begin{tabular}{|c|c|}
\hline Conhecimento da & Conhecimento da \\
experiência & realidade \\
Conhecimento & Conhecimento \\
simultâneo & seqüencial \\
Conhecimento na & Conhecimento na \\
prática & teoria \\
\hline
\end{tabular}

Fonte: NONAKA, I.; TAKEUCHI, H. Criação de conhecimento na empresa: como as empresas japonesas geram a dinâmica da inovação. Rio de Janeiro: Campus, 1997, p.66.

Criar novos conhecimentos é recriar a empresa e todos seus colaboradores em um processo contínuo. Não é de responsabilidade de poucos, mas sim de todos na organização. Segundo Drucker (1992), a organização tem que estar preparada para abandonar o conhecimento obsoleto e aprender a criar o novo através dos seguintes pontos: melhoria contínua de todas as atividades; desenvolvimento de novas aplicações a partir de seus próprios sucessos; e inovação contínua como um processo organizado.

Segundo Murray (1996), gestão do conhecimento é a estratégia que converte os bens intelectuais das organizações, tanto as informações como o talento dos membros, em maior produtividade, novo valor e aumento da competitividade. Contribuindo com esta visão, Garvin (1993) afirma que uma organização baseada no conhecimento é uma organização de aprendizagem que reconhece o conhecimento como recurso estratégico, e cria conhecimento que pode ser processado internamente e utilizado externamente, aproveitando o potencial de seu capital intelectual, em que o trabalhador do conhecimento é o componente crítico.

Fialho (2001) afirma que a gestão do conhecimento depende muito da gestão da infra-estrutura da tecnologia da informação, pois esta permite que as pessoas rompam com os antigos paradigmas e criem novas formas de viver, transpondo limites e criando formas de aprimoramento contínuo. Entretanto, na era do conhecimento, são o cérebro e o talento das pessoas que ocupam o centro do modelo do capital intelectual.

A utilização da gestão do conhecimento nas empresas pode desencadear melhores decisões e ações em marketing, vendas, produção, logística, recursos humanos, entre outras áreas, que ajudarão a atingir plenamente os objetivos estratégicos da organização. Assim, as empresas têm como propulsor para $\mathrm{o}$ futuro o seu "capital intelectual", diferenciando-se, no mercado, pelo que sabem, e tendo o conhecimento como sua maior vantagem competitiva, (BUENO et al, 2004).

De forma a contribuir com a perspectiva de Nonaka e Takeuchi (1997), Simon (1991) afirma que a aprendizagem organizacional ocorre de duas maneiras distintas: (1) quando os membros da organização aprendem e (2) quando ocorre a contratação de pessoas que tragam novos conhecimentos à organização. Com isso, considera-se que o conhecimento encontra-se depositado principalmente nas pessoas as quais são os elementos da aprendizagem e que constroem novos conhecimentos e geram a aprendizagem através de processos experienciais (KOLB, 1984) e cognitivos (SENGE, 1990). Assim, partindo deste pressuposto, pode-se inferir que as características individuais e psicológicas podem vir a influenciar o modo com que as pessoas aprendem e disseminam novos conhecimentos.

Entretanto, como pressuposto básico para a gestão da aprendizagem e do conhecimento organizacional reside no fato de que é necessário criar, adquirir e transferir conhecimentos (GARVIN, 1994) que permita à organização modificar suas rotinas, estratégias e redirecionar seu foco de mercado. Busca-se com isso evitar que a organização fique excessivamente vinculada ao conhecimento depositado em seus funcionários, disseminando o conhecimento no ambiente 
organizacional. Como forma de pensar a aprendizagem organizacional, encontra-se o trabalho seminal de Argyris e Schön (1996) e o modelo da aprendizagem em circuito simples e duplo. Para os autores, quando um erro ou desvio é detectado e corrigido sem questionar ou alterar os valores subjacentes ao sistema observa-se uma aprendizagem em circuito simples. Desse modo, apenas a ação foi alterada sem ser realizado nenhum questionamento a respeito dos valores e teorias em prática. Já a aprendizagem em circuito duplo representa a forma de aprender através do questionamento dos valores e teorias em uso. A aprendizagem em circuito simples é indicada para rotinas e aspectos repetitivos da organização. Em contra partida, a aprendizagem em circuito duplo é mais indicada para aspectos complexos e não programáveis da organização já que esta busca mudanças mais profundas e consideradas estratégicas para uma organização.

Focalizando os pressupostos da aprendizagem organizacional nas capacidades cognitivas e de memória dos indivíduos, pode-se afirmar que estas capacidades individuais são condicionantes cruciais para o desenvolvimento de uma aprendizagem a nível organizacional (KIM, 1993). Corroborando com esta premissa, o conceito de modelos mentais (SENGE, 1990) propõe um entendimento a respeito de como as informações são processadas, percebidas e interpretadas pelos indivíduos. Assim, os modelos mentais compartilhados podem ser considerados como o elo entre o nível de aprendizagem individual e organizacional (KIM, 1993; SENGE, 1990). Parte-se do pressuposto de que quando os modelos mentais são explicitados e compartilhados dentro de um grupo, a base do significado compartilhado na organização aumenta. Isso resulta em um crescimento da capacidade da organização para coordenação de suas ações gerando, assim, aprendizagem em nível grupal e organizacional. Este compartilhamento e busca por um significado coletivo pode ser corroborado pelo modelo da espiral do conhecimento (NONAKA e TAKEUCHI, 1997).

\section{Orientação para a aprendizagem}

Como forma de desenvolver aspectos estratégicos organizacionais, a orientação para a aprendizagem é vista como uma postura que visa desenvolver a aprendizagem e a gestão do conhecimento organizacional. A orientação para a aprendizagem pode ser definida como um grupo de valores que influenciam o grau com que uma organização considera-se satisfeita com relação as suas teorias em uso (ARGYRIS e SCHON, 1978), seus modelos mentais (DE GEUS, 1988) e sua lógica dominante (BETTIS e PRAHALAD, 1995) que pode estar ou não estar baseada no mercado. Organizações com uma forte orientação para a aprendizagem incentivam, e até mesmo exigem, que seus membros e funcionários constantemente questionem as normas organizacionais vigentes que orientam suas atividades de processamento das informações de mercado assim como as ações organizacionais (GARVIN, 1993; SINKULA, 1994; SINKULA, BAKER e NOORDEWIER, 1997).

Valores que são constantemente associados com as capacidades da aprendizagem organizacional circundam o (1) compromisso com a aprendizagem, (2) mente aberta, e (3) visão compartilhada (SENGE, 1990; SINKULA, BAKER e NOORDEWIER, 1997). Empresas que estão comprometidas com a aprendizagem valorizam a necessidade de entender as causas e efeitos de suas ações (SHAW e PERKINS, 1991) já que esta postura é necessária para que as empresas possam detectar e corrigir os erros de suas teorias em uso. 
O compromisso com a aprendizagem diz respeito aos princípios da aprendizagem discutidos por Senge (1990). Mente aberta está associada à idéia de "desaprender a aprender". O conceito de "desaprendizagem" (NYSTROM e STARBUCK, 1984). Este espírito de "desaprendizagem" e considerado como o centro da mudança organizacional e o processo de aperfeiçoamento e aprendizagem. A visão compartilhada gera uma propensão ao compartilhamento de uma lógica dominante e resultados conjuntamente esperados(DOUGHERTY, 1989). A falta de um foco organizacional compreendido de modo geral e compartilhado por todos gera uma redução na motivação para aprender (TOBIN, 1993). Esta visão compartilhada proporciona um senso comum de direção e propósito.

Enquanto que comportamentos adotados para uma postura orientada para o mercado são mais rapidamente alterados (DICKSON, 1996) e proporcionam um efeito positivo na lucratividade da empresa de um modo mais imediato (NARVER e SLATER, 1990), a orientação para a aprendizagem é mais demorada de ser implementada já que é o resultado de atitudes, compromissos e processos gerenciais cuidadosamente cultivadas e que são desenvolvidos e acumulados ao longo do tempo e de forma progressiva (GARVIN, 1993).

Enquanto uma orientação para o mercado possa gerar a uma aprendizagem em circuito simples (single-loop learning) adaptativa (NARVER e SLATER, 1995) ela não irá levar a organização a uma aprendizagem em circuito duplo (doubleloop learning) geradora de novos conhecimentos a menos que seja acompanhada de uma forte orientação para a aprendizagem (ARGYRIS e SCHON, 1978; SENGE, 1990).

\section{Metodologia}

Este estudo tem a finalidade de identificar a orientação para a aprendizagem existente na empresa estudada. Assim, o mesmo se caracteriza por seu um estudo de caso (YIN, 2001) descritivo já que se pretende descrever uma realidade ou fenômeno organizacional. Ainda, o estudo se caracteriza como sendo qualitativo e quantitativo. A etapa qualitativa foi desenvolvida através de entrevistas semi-estruturadas com os principais dirigentes da empresa. Já a etapa quantitativa foi conduzida foi conduzida através de uma pesquisa de levantamento interno (survey) (BABBIE, 1999) com a aplicação de questionário a população dos 40 colaboradores do nível administrativo.

Para a coleta de dados quantitativos foi adotada a escala proposta por Sinkula, Baker, e Noordewier (1997) para a avaliação da Orientação para a Aprendizagem da empresa SUPERTEX composta de 18 itens divididos em 3 dimensões de análise (variáveis latentes) sendo (1) o comprometimento para com a aprendizagem, (2) a visão compartilhada, e (3) a "mente aberta". A escolha desta escala se deu pelo motivo desta já ter sido amplamente testada e validada em demais estudos de alto impacto no meio acadêmico e científico. Os 18 itens da escala foram avaliados através de uma escala Likert de 5 pontos indo de Concordo Totalmente (1) até Discordo Totalmente (5). Foram entregues, assim, 40 questionários para todos os colaboradores do setor administrativo e obteve-se um retorno de 38 questionários válidos o que proporciona uma grande capacidade de inferência estatística para o setor administrativo da empresa já que se obteve o retorno de praticamente toda a população. A técnica de obtenção dos dados através do instrumento já descrito foi não presencial, pois não contou com a presença do pesquisador. Assim, os questionários (formulários) foram entregues aos admi- 
nistradores da empresa e recolhidos após o seu devido preenchimento. para a confiabilidade interna do instrumento $(\alpha=0,780)$ e para as dimensões

\begin{tabular}{|c|c|c|c|}
\hline Dimensões & $\begin{array}{c}\text { Iten } \\
\mathrm{S}\end{array}$ & Descrição da Variável & $\begin{array}{l}\boldsymbol{\alpha} \\
\mathbf{0 , 7} \\
\mathbf{8 0}\end{array}$ \\
\hline \multirow{6}{*}{$\begin{array}{l}\text { Comprometiment } \\
\text { o para com a } \\
\text { aprendizagem }\end{array}$} & V.1 & $\begin{array}{l}\text { Administradores e gerentes basicamente concordam que a habilidade } \\
\text { para a aprendizagem desta empresa é a chave para nossa vantagem } \\
\text { competitiva. }\end{array}$ & \multirow{6}{*}{$\begin{array}{r}0,5 \\
11\end{array}$} \\
\hline & V.2 & $\begin{array}{l}\text { Os valores básicos desta empresa incluem a aprendizagem como chave } \\
\text { para a melhoria. }\end{array}$ & \\
\hline & V.3 & $\begin{array}{l}\text { O senso nesta empresa é que a aprendizagem dos funcionários é um } \\
\text { investimento, e não uma despesa. }\end{array}$ & \\
\hline & V.4 & $\begin{array}{l}\text { Aprendizagem nesta organização é vista como uma mercadoria-chave } \\
\text { necessária para garantir a sobrevivência organizacional }\end{array}$ & \\
\hline & V.5 & $\begin{array}{l}\text { Nossa cultura é aquela que não faz da aprendizagem de nossos } \\
\text { empregados uma prioridade. (R) }\end{array}$ & \\
\hline & V.6 & $\begin{array}{l}\text { A sabedoria comum nesta empresa é a de que uma vez que tenhamos } \\
\text { parado de aprender, colocamos em risco nosso futuro. }\end{array}$ & \\
\hline \multirow{6}{*}{$\begin{array}{l}\text { Visão } \\
\text { compartilhada }\end{array}$} & V.7 & $\begin{array}{l}\text { Há uma noção clara de quem somos e para onde estamos indo como esta } \\
\text { empresa. }\end{array}$ & \multirow{6}{*}{$\begin{array}{l}0,7 \\
29\end{array}$} \\
\hline & V.8 & $\begin{array}{l}\text { Existe um consenso geral da visão de nossa empresa através de todos os } \\
\text { níveis, funções e departamentos. }\end{array}$ & \\
\hline & V.9 & $\begin{array}{l}\text { Todos os funcionários estão comprometidos com os objetivos desta } \\
\text { empresa. }\end{array}$ & \\
\hline & V.10 & $\begin{array}{l}\text { Os funcionários se vêem como parceiros no mapeamento das direções da } \\
\text { empresa. }\end{array}$ & \\
\hline & V.11 & $\begin{array}{l}\text { A liderança do topo da empresa acredita em compartilhar a sua visão } \\
\text { com os níveis mais baixos da organização. }\end{array}$ & \\
\hline & V.12 & Nós não temos uma visão bem definida para toda a empresa. (R) & \\
\hline \multirow{6}{*}{ "mente aberta" } & V.13 & $\begin{array}{l}\text { Nós não temos medo de refletir criticamente sobre os nossos } \\
\text { pressupostos comuns sobre a forma como fazemos negócios. }\end{array}$ & \multirow{6}{*}{$\begin{array}{l}0,6 \\
91\end{array}$} \\
\hline & V.14 & $\begin{array}{l}\text { Os administradores e gerentes desta empresa não querem que a sua } \\
\text { "visão de mundo" seja questionada. (R) }\end{array}$ & \\
\hline & V.15 & Nossa unidade de negócios valoriza muito a mentalidade aberta. & \\
\hline & V.16 & $\begin{array}{l}\text { Administradores e gerentes incentivam os trabalhadores a pensar de } \\
\text { modo criativo e sob novas perspectivas. }\end{array}$ & \\
\hline & V.17 & $\begin{array}{l}\text { Uma ênfase na inovação constante não é uma parte de nossa cultura } \\
\text { corporativa. (R) }\end{array}$ & \\
\hline & V.18 & Ideias originais são altamente valorizadas nesta organização. & \\
\hline
\end{tabular}

A seguir são apresentados no quadro 02 os itens da escala proposta por Sinkula, Baker, e Noordewier (1997) para a avaliação da Orientação para a Aprendizagem. Observa-se também no quadro os valores do alfa (CRONBACH, 1951) definidas pelos autores do instrumento: (1) Comprometimento para com a aprendizagem $(\alpha=0,511)$; (2) Visão compartilhada $(\alpha=0,729)$; e (3) Mente Aberta $(\alpha=0,691)$. Considera-se que os valores de alfa foram satisfatórios apesar de a pri-

Quadro 02 - Escala de Avaliação da Orientação para a Aprendizagem.

$\alpha=$ confiabilidade interna (CRONBACH, 1951); (R) codificação reversa. As variáveis são mensuradas através de escala Likert de 5 pontos $(1=$ concordo totalmente $/ 5=$ discordo totalmente $)$.

A tabulação e análise dos dados se

meira dimensão ter apresentado um valor relativamente baixo. deram com o auxílio do software SPSS for Windows 15.0. Nesta etapa de tratamento 
e análise dos dados utilizou-se de análises descritivas e análises de frequiência dos dados. Também foram utilizadas análises de correlação de Spearman (devido ao pequeno número de observações) e testes

de diferenças entre grupos (Teste $\mathrm{T}$ de Student e Teste U de Mann-Whitney). Os resultados são apresentados na subseção a seguir.

\section{Resultados do estudo}

Inicialmente são apresentadas as informações qualitativas obtidas através da primeira etapa do estudo que foi conduzida através de entrevistas semi-estruturadas com os dirigentes. Em seguida são analisados os dados quantitativos obtidos através do estudo de levantamento.

\subsection{Caracterização da supertex}

A empresa SUPERTEX nasceu em Setembro de 1974, denominada de "Helvio Basso", com características de empresa familiar (de origem Italiana), iniciou suas atividades mediante a comercialização de areia em Santa Maria e região (RS). Sua primeira instalação foi na estrada Municipal Ângelon Berleze em Camobi, junto à residência num pequeno chalé, o qual existe até hoje. Inicialmente a empresa contava apenas com um funcionário e possuía um caminhão para fazer a comercialização de "areia". Ocorreu em 1975, uma parceria entre a Helvio Basso e a Brita Pinhal de Itaara, onde começou-se a comercializar brita, essa parceria dura até os dias de hoje.

Foi comprada em 1982 a primeira areeira, assim além de comercializar areia passaram a produzir para vender. Em 1984, houve uma grande enchente, até então nunca visto, e junto com ela levou o estoque de areia que a empresa depositava próximo ás margens do Rio Vacacaí, deixando-os numa situação financeira muito difícil. Foi a partir daí que o fundador Helvio Basso tomou a decisão de abandonar os laços familiares, mudando a localização da empresa para BR392 KM2, Faixa de São Sepé, onde está situada até os dias de hoje conforme mostra o Anexo A. A nova Instalação ficou mais próxima das areeiras onde produziam, reduzindo a distância e os custos com transporte, tornando a empresa mais competitiva.

A partir dai foram surgindo novas idéias, começou a vislumbrar a possibilidade de diversificação de seus produtos que até então era somente areia e brita. Em 1990, iniciou-se a produção de argamassa de forma artesanal com uma pequena usina instalada no fundo do pátio da empresa na BR392. Nessa época o único filho do Senhor Helvio Bossa, Elizandro Basso, com 16 anos, começou a participar da administração da empresa, fazendo serviços de banco e cobranças. Com todo o trabalho e dedicação do fundador o objetivo proposto logo foi alcançado: ser o número um em vendas de areia e argamassa. Em 1992 identificou-se a necessidade de buscar outro produto que pudesse ser implementado, iniciando-se nesse mesmo ano a revenda e distribuição de cimento em Santa Maria. Foi um pouco complicado, pois naquela época as indústrias de cimento já tinham seus escolhidos e não queriam abrir novos distribuidores.

A empresa sempre preservou a filosofia de ser a número um com tudo que trabalhasse e implantasse, assim foi consolidado a "Helvio Basso o Rei da Areia", sendo que os princípios que sempre nortearam a mesma desde seu início foram à honestidade, qualidade e agilidade.

Havia em Santa Maria apenas uma empresa que trabalha com concreto usinado, surgindo assim, em 1995, a idéia de entrar neste mercado, sendo que com o passar do tempo essa tecnologia substituiu a venda de areia e brita. Nessa época a empresa já contava com 30 funcionários. 
Com o objetivo de usar concreto usinado, argamassa e também matérias de construção em 1997, foi decidido montar o projeto para a implementação da REITEX Ind. Comércio de Artefatos de Concreto Ltda. Depois de um ano (1998), o projeto foi aprovado pela RECONVERSUL (programa do governo para metade sul do estado). Com a aprovação do mesmo e prevendo um crescimento da empresa, houve a necessidade de profissionalizar a empresa, iniciando no setor contábil, contratando uma empresa que pudesse além de fazer contabilidade, prestar uma assessoria contábil e também gerencial auxiliando nas tomadas de decisões.

Em Outubro deste ano após o início da construção da nova sede, a empresa perde seu fundador, por problemas de saúde. A partir desse momento a empresa passou a ser administrada pelo seu filho Elizandro Basso o qual gerencia a mesma até os dias de hoje.

No dia 26 de Abril de 1999 a REITEX então inicia seu primeiro carregamento de concreto para o cliente Dr. Clóvis Blattes Flores na Rua Major Duarte.

A empresa passava novamente por desafios, empresa nova, mercado novo e a necessidade de conquistar a confiança dos clientes, pois, agora a empresa passava a ser gerenciada por um jovem de 23 anos. Mas através de muito esforço e seguindo a filosofia da qualidade, agilidade e honestidade deixada pelo seu pai, Elizandro está dando continuidade ao trabalho.

Em 2002, ocorreu uma mudança no nome da empresa onde passou a se chamar SUPERTEX - Seleta Indústria Comércio e Serviço de Concretagem Ltda.

Juntamente com o desenvolvimento das concreteiras, a SUPERTEX manteve alguns "negócios" desde sua origem e desenvolveu outros novos, a empresa totaliza hoje cinco negócios agregados às usinas de concreto, que são: areeiras, loja de materiais de construção, pisos industriais, locação de equipamentos e sistema Mormix.

Para a viabilização das atividades da empresa, tornou-se necessário a aquisição de um grande número de veículos na sua frota, para auxiliar na entrega de produtos a clientes e no abastecimento interno de insumos nos pontos de fabricação, seja de concreto ou de areia, ou seja, atualmente a empresa transporta com recursos próprios (frota e funcionários) todos os insumos que utiliza, bem como, toda a entrega dos produtos que vende. Esta decisão de manter uma frota própria, e não de terceiros, direcionou a empresa a manter um grande número de funcionários ligados à condução (motoristas) e administração de frota (gerentes e auxiliares), o que se tornou uma característica marcante dentro da rotina da empresa. A administração e o controle da frota tornaram-se umas das prioridades internas na empresa, para tanto foram desenvolvidos setores internos especializados, como: setor de manutenção, de pneus, de logística, de condução, de médias de combustíveis, de segurança, de tacógrafos, rastreamento online $24 \mathrm{~h}$, etc.

Em Santa Maria estrutura-se o centro administrativo da empresa, que presta suporte as demais filiais, através dos setores: financeiro, recursos humanos, cobrança, análise de crédito, compras, informática, controle tecnológico, administração de frota, estoque e direção. Os setores possuem uma equipe de funcionários que atuam nas rotinas de cada setor. É também em Santa Maria que a empresa desenvolve ações para o gerenciamento de RH. As contratações seguem um processo realizado na sede da empresa, que passam por: análise de currículo, consulta de referências, avaliação psicológica e avaliação prática.

A empresa conta hoje com aproximadamente 300 colaboradores diretos, possui 10 (dez) unidade de negócios sendo que oito estão instaladas no Rio 
Grande do Sul, em Santa Maria, Panambi, Ijuí, Ibirubá, Carazinho, Maquiné, Passo Fundo, Porto Alegre e duas em Santa Catarina, em São José e Camboriú. Também conta com uma frota moderna com mais de 150(cento e cinquienta) veículos entre caminhões, máquinas e veículos.

\subsection{Resultados quantitativos}

Ao analisar o perfil dos entrevistados do setor administrativo da SUPERTEX pode-se perceber que os mesmos possuem idade mínima de 18 anos e máxima de 45 anos, tendo assim uma média de 29 anos. Quanto ao sexo observou-se que 21 dos entrevistados são do sexo masculino, obtendo dessa forma uma porcentagem de 55,3\%, e 17 colaboradores entrevistados são do sexo feminino, tendo assim uma porcentagem de $44,7 \%$. Quanto ao tempo de empresa verificou-se que os entrevistados possuem um tempo mínimo de 3 meses e um tempo máximo de 23 anos, e uma média de 3,65 anos. No que diz respeito ao tempo no cargo atual obteve-se um tempo mínimo de 3 meses e um tempo máximo de 7 anos tendo assim uma média de 2,47 anos.

A seguir é apresentada a tabela 01 com os resultados da pesquisa, sendo que a mesma é composta pelos seguintes dados: número de entrevistados, média, desvio padrão. Para a elaboração da análise dos dados foi levado em consideração a média obtida em cada questão, onde considerou-se que se a média varia de 1 à 1,5 o entrevistado concorda fortemente com a questão; de 1,5 à 2,5 representa concordância média; de 2,5 à 3,5 representa indiferença; 3,5 à 4,5 representa discordância média; e de 4,5 à 5 representa discordância fortemente.

Tabela 01 - Tabulação Descritiva

\begin{tabular}{|c|c|c|c|c|}
\hline Item & Descrição & $\mathbf{N}$ & Média & $\begin{array}{l}\text { Desvio } \\
\text { padrão }\end{array}$ \\
\hline V.1 & $\begin{array}{l}\text { Administradores e gerentes basicamente concordam que a habilidade para a } \\
\text { aprendizagem desta empresa é a chave para nossa vantagem competitiva. }\end{array}$ & 38 & 1,3421 & ,53405 \\
\hline V.2 & $\begin{array}{l}\text { Os valores básicos desta empresa incluem a aprendizagem como chave para } \\
\text { a melhoria. }\end{array}$ & 38 & 1,3947 & ,59455 \\
\hline V.3 & $\begin{array}{l}\text { O senso nesta empresa é que a aprendizagem dos funcionários é um } \\
\text { investimento, e não uma despesa. }\end{array}$ & 38 & 1,3684 & ,81940 \\
\hline V.4 & $\begin{array}{l}\text { Aprendizagem nesta organização é vista como uma mercadoria-chave } \\
\text { necessária para garantir a sobrevivência organizacional. }\end{array}$ & 38 & 1,5789 & ,59872 \\
\hline V.5 & $\begin{array}{l}\text { Nossa cultura é aquela que não faz da aprendizagem de nossos empregados } \\
\text { uma prioridade. (R) }\end{array}$ & 38 & 3,9211 & 1,44037 \\
\hline V.6 & $\begin{array}{l}\text { A sabedoria comum nesta empresa é a de que uma vez que tenhamos parado } \\
\text { de aprender, colocamos em risco nosso futuro. }\end{array}$ & 38 & 1,9211 & 1,14801 \\
\hline V.7 & $\begin{array}{l}\text { Há uma noção clara de quem somos e para onde estamos indo como esta } \\
\text { empresa. }\end{array}$ & 38 & 1,9737 & 1,07771 \\
\hline V.8 & $\begin{array}{l}\text { Existe um consenso geral da visão de nossa empresa através de todos os } \\
\text { níveis, funções e departamentos. }\end{array}$ & 38 & 2,2632 & ,92076 \\
\hline V.9 & $\begin{array}{l}\text { Todos os funcionários estão comprometidos com os objetivos desta } \\
\text { empresa. }\end{array}$ & 38 & 2,3421 & 1,09733 \\
\hline V.10 & $\begin{array}{l}\text { Os funcionários se vêem como parceiros no mapeamento das direções da } \\
\text { empresa. }\end{array}$ & 38 & 2,0789 & ,94101 \\
\hline V.11 & $\begin{array}{l}\text { A liderança do topo da empresa acredita em compartilhar a sua visão com os } \\
\text { níveis mais baixos da organização. }\end{array}$ & 38 & 1,9211 & 1,21659 \\
\hline V.12 & Nós não temos uma visão bem definida para toda a empresa. (R) & 38 & $\mathbf{3 , 3 1 5 8}$ & 1,27566 \\
\hline V.13 & $\begin{array}{l}\text { Nós não temos medo de refletir criticamente sobre os nossos pressupostos } \\
\text { comuns sobre a forma como fazemos negócios. }\end{array}$ & 38 & 1,9474 & ,92845 \\
\hline V.14 & Os administradores e gerentes desta empresa não querem que a sua "visão & 38 & 3,8421 & 1,30542 \\
\hline
\end{tabular}




\begin{tabular}{llccc}
\hline \multicolumn{2}{c}{ de mundo" seja questionada. (R) } & & \\
\hline V.15 & Nossa unidade de negócios valoriza muito a mentalidade aberta. & 38 & $\mathbf{1 , 9 2 1 1}$ &, 94101 \\
\hline V.16 & $\begin{array}{l}\text { Administradores e gerentes incentivam os trabalhadores a pensar de modo } \\
\text { criativo e sob novas perspectivas. }\end{array}$ & 38 & $\mathbf{1 , 6 5 7 9}$ &, 70811 \\
\hline V.17 & $\begin{array}{l}\text { Uma ênfase na inovação constante não é uma parte de nossa cultura } \\
\text { corporativa. (R) }\end{array}$ & 38 & $\mathbf{3 , 9 2 1 1}$ & 1,21659 \\
\hline V.18 & Ideias originais são altamente valorizadas nesta organização. & 38 & $\mathbf{1 , 8 1 5 8}$ &, 95451 \\
\hline
\end{tabular}

Fonte: Dados coletados (2010).

Para descrever as variáveis do estudo, foram organizadas estas em blocos onde o primeiro bloco avalia o comprometimento da empresa para com a aprendizagem (V.1 à V.6). Observando-se o valor de média obtido na V.1 (1,3421) conclui-se que os colaboradores do nível administrativo da empresa concordam fortemente que a habilidade para a aprendizagem da SUPERTEX é a chave para a sua vantagem competitiva. A média obtida na V.2 $(1,3947)$ nos mostra que o nível administrativo concorda fortemente que entre os valores básicos da empresa inclui-se a aprendizagem como chave para a melhoria. No que diz respeito que a aprendizagem dos funcionários na empresa é um investimento, e não uma despesa obteve-se uma média V.3 $(1,3684)$, o que nos mostra que os entrevistados do nível administrativo concordam fortemente com a questão. Ao analisar a questão, a aprendizagem nesta organização é vista como uma mercadoria-chave necessária para garantir a sobrevivência organizacional obteve-se uma média V.4 $(1,5789)$ o que nos mostra que os entrevistados do nível administrativo concordam com a questão. Ao observar o valor de média obtido na V.5 (3,9211) conclui-se que os entrevistados do setor administrativo da empresa discordam que a cultura da empresa é aquela que não faz da aprendizagem dos empregados uma prioridade. E, finalmente com a média obtida na questão V.6 $(1,9211)$ conclui-se que os colaboradores do nível administrativo concordam que a sabedoria comum na empresa é a de que uma vez que tenham parado de aprender, colocam em risco o seu futuro.

O segundo bloco de questões objetiva avaliar a visão compartilhada dos colaboradores frente à empresa (V.7 à V.12) na visão dos dirigentes e gestores do setor administrativo. Ao analisar a questão V.7 pode-se perceber através da média $(1,9737)$ que os colaboradores entrevistados concordam que há uma noção clara de quem são e para onde estão indo com a empresa em estudo. A média obtida na V.8 $(2,2632)$ nos mostra que os colaboradores concordam com a questão que diz respeito há existência de um consenso geral da visão da empresa através de todos os níveis, funções e departamentos. Obteve-se na V.9 uma média de 2,3421, sendo assim os colaboradores concordam que grande parte os funcionários estão comprometidos com os objetivos da empresa. Na questão V.10 onde os colaboradores foram questionados se eles se viam como parceiros no mapeamento das direções da empresa obteve-se uma média de 2,0789 onde pode-se afirmar que eles concordam com a questão. Ao observar o valor de média obtido na V.11 (1,9211) verificou-se que os colaboradores concordam com a questão em que a liderança do topo da empresa acredita em compartilhar a sua visão com os níveis mais baixos da organização. Com a média obtida na V.12 (3,3158) pode-se afirmar que para os colaboradores entrevistados é indiferente a questão de não terem uma visão bem definida para toda a empresa.

O terceiro bloco contém questões que avaliam a "mente aberta" dos entrevistados frente à empresa em estudo (V.13 
à V.18). Observando a questão V.13 $(1,9474)$ pode-se perceber que os colaboradores entrevistados concordam com a afirmação "Nós não temos medo de refletir criticamente sobre os nossos pressupostos comuns sobre a forma como fazemos negócios". Ao analisar a questão, V.14 (3,8421) pode-se afirmar que os colaboradores entrevistados, discordam que os administradores e gerentes da empresa em estudo não querem que a sua "visão de mundo" seja questionada. A média obtida na V.15 $(1,9211)$ nos mostra que os colaboradores concordam que a SUPERTEX valoriza muito a mentalidade aberta. Observando-se o valor de média obtida na V.16 $(1,6579)$, conclui-se que os colaboradores entrevistados concordam que os administradores e gerentes incentivam os trabalhadores a pensar de modo criativo e sob novas perspectivas. Ao analisar a questão "Uma ênfase na inovação constante não é uma parte de nossa cultura corporativa." obteve-se uma média V.17 $(3,9211)$, o que nos mostra que os colaboradores entrevistados discordam da mesma. A média obtida na V.18 $(1,8158)$ nos mostra que os colaboradores concordam que os ideais originais são altamente valorizados na SUPERTEX.

Para verificar se existem diferenças significativas de percepção entre os dirigentes do sexo masculino e feminino utilizou-se do Teste T de Student (pressupondo uma distribuição normal das variáveis) e do Teste U de Mann Whitney (pressupondo uma distribuição nãonormal das variáveis). A Tabela 02 abaixo apresenta os resultados do teste para os 18 itens da escala de Orientação para a Aprendizagem avaliados. Verifica-se que os itens V.3, V.7 e V.8 apresentam diferenças significativas entre o sexo dos respondentes. Os homens apresentam níveis de concordância significativamente diferentes para a afirmação de que "o senso nesta empresa é que a aprendizagem dos funcionários é um investimento, e não uma despesa" ( $p<0,05)$, para a afirmação que diz que "há uma noção clara de quem somos e para onde estamos indo como esta empresa" $(\mathrm{p}<0,000)$ e para a afirmação de que "existe um consenso geral da visão de nossa empresa através de todos os níveis, funções e departamentos" $(\mathrm{p}<0,000)$. Isso pode significar que as mulheres do nível estratégico da empresa não compartilham desta percepção de que exista um senso comum a respeito em termos de direção de negócio e visão compartilhada entre os níveis organizacionais da empresa.

Tabela 02 - Teste T de Student e Teste U de Mann Wittney para Grupos Independentes (SEXO)

\begin{tabular}{ccccccc}
\hline Itens & $\begin{array}{c}\text { Média } \\
\text { (Masculino) }\end{array}$ & $\begin{array}{c}\text { Média } \\
\text { (Feminino) }\end{array}$ & $\begin{array}{c}\text { Valor de } \\
\text { T }\end{array}$ & p-valor (T) & $\begin{array}{c}\text { Valor de } \\
\text { U }\end{array}$ & p-valor (U) \\
\hline V.1 & 1,285714 & 1,411765 & $-0,71871$ & 0,476962 & 163,50 & 0,659671 \\
\hline V.2 & 1,285714 & 1,529412 & $-1,26656$ & 0,213447 & 138,50 & 0,240270 \\
\hline V.3 & $\mathbf{1 , 0 9 5 2 3 8}$ & $\mathbf{1 , 7 0 5 8 8 2}$ & $\mathbf{- 2 , 4 3 1 0 6}$ & $\mathbf{0 , 0 2 0 1 6 3 *}$ & $\mathbf{1 0 5 , 5 0}$ & $\mathbf{0 , 0 3 2 1 0 4 *}$ \\
\hline V.4 & 1,428571 & 1,764706 & $-1,76969$ & 0,085250 & 130,50 & 0,158784 \\
\hline V.5 (R) & 3,714286 & 4,176471 & $-0,98307$ & 0,332133 & 162,00 & 0,628099 \\
\hline V.6 & 2,142857 & 1,647059 & 1,33779 & 0,189355 & 155,00 & 0,490252 \\
\hline V.7 & $\mathbf{1 , 3 8 0 9 5 2}$ & $\mathbf{2 , 7 0 5 8 8 2}$ & $\mathbf{- 4 , 7 3 4 9 2}$ & $\mathbf{0 , 0 0 0 0 3 4 * *}$ & $\mathbf{6 0 , 5 0}$ & $\mathbf{0 , 0 0 0 5 3 2 * *}$ \\
\hline V.8 & $\mathbf{1 , 8 0 9 5 2 4}$ & $\mathbf{2 , 8 2 3 5 2 9}$ & $\mathbf{- 4 , 0 0 2 3 7}$ & $\mathbf{0 , 0 0 0 2 9 9 * *}$ & $\mathbf{7 4 , 0 0}$ & $\mathbf{0 , 0 0 2 1 5 6 * *}$ \\
\hline V.9 & 2,285714 & 2,411765 & $-0,34788$ & 0,729956 & 158,00 & 0,547284 \\
\hline V.10 & 2,095238 & 2,058824 & 0,11702 & 0,907495 & 177,50 & 0,976579 \\
\hline V.11 & 2,047619 & 1,764706 & 0,70795 & 0,483533 & 172,50 & 0,860179 \\
\hline
\end{tabular}




\begin{tabular}{ccccccc}
\hline V.12 (R) & 3,476190 & 3,117647 & 0,85842 & 0,396341 & 147,50 & 0,362774 \\
\hline V.13 & 1,809524 & 2,117647 & $-1,01769$ & 0,315614 & 143,50 & 0,304174 \\
\hline V.14 (R) & 3,714286 & 4,000000 & $-0,66578$ & 0,509795 & 173,50 & 0,883298 \\
\hline V.15 & 1,761905 & 2,117647 & $-1,16429$ & 0,251963 & 141,00 & 0,270933 \\
\hline V.16 & 1,476190 & 1,882353 & $-1,81148$ & 0,078417 & 125,50 & 0,119717 \\
\hline V.17 (R) & 3,714286 & 4,176471 & $-1,17023$ & 0,249596 & 149,50 & 0,394560 \\
\hline V.18 & 1,714286 & 1,941176 & $-0,72388$ & 0,473819 & 134,50 & 0,196446 \\
\hline
\end{tabular}

* Diferença é significativa ao nível de 0,05 . ** Diferença é significativa ao nível de 0,01 .

tempo de empresa e o tempo de cardo dos respondentes. O objetivo desta análise é

Também se realizou uma análise de Correlação de Spearman devido ao pequeno tamanho da amostra. Buscou-se identificar o nível de correlação existente entre os 18 itens da escala de avaliação da Orientação para a Aprendizagem com a Idade, o verificar se estas variáveis de tempo podem estar correlacionadas com as avaliações dos respondentes. Os dados da análise de Correlação são apresentados na Tabela 03 abaixo.

Tabela 03 - Correlação de Spearman

\begin{tabular}{|c|c|c|c|c|}
\hline & & Idade & Tempo de Empresa & Tempo no Cargo \\
\hline V.1 & Coeficiente & $-0,295(0,072)$ & $-0,380 *(0,022)$ & $-0,231(0,182)$ \\
\hline V.2 & Coeficiente & $-0,190(0,254)$ & $-0,407 *(0,014)$ & $-0,264(0,125)$ \\
\hline V.3 & Coeficiente & $-0,143(0,391)$ & $-0,407 *(0,014)$ & $-0,310(0,070)$ \\
\hline V.4 & Coeficiente & $-0,077(0,646)$ & $-0,292(0,084)$ & $-0,161(0,356)$ \\
\hline V.5 (R) & Coeficiente & $-0,152(0,363)$ & $-0,221(0,195)$ & $-0,347 *(0,041)$ \\
\hline V.6 & Coeficiente & $-0,143(0,391)$ & $-0,105(0,542)$ & $0,006(0,971)$ \\
\hline V.7 & Coeficiente & $0,011(0,949)$ & $-0,156(0,364)$ & $-0,046(0,792)$ \\
\hline $\mathrm{V} .8$ & Coeficiente & $0,005(0,978)$ & $0,090(0,603)$ & $0,173(0,321)$ \\
\hline V.9 & Coeficiente & $-0,181(0,277)$ & $-0,130(0,451)$ & $-0,030(0,864)$ \\
\hline V.10 & Coeficiente & $0,213(0,198)$ & $0,053(0,758)$ & $0,183(0,293)$ \\
\hline V.11 & Coeficiente & $0,156(0,350)$ & $0,164(0,340)$ & $0,195(0,262)$ \\
\hline $\begin{array}{l}\text { V.12 } \\
\text { (R) }\end{array}$ & Coeficiente & $-0,224(0,176)$ & $-0,294(0,082)$ & $-0,535 * *(0,001)$ \\
\hline V.13 & Coeficiente & $-0,157(0,345)$ & $-0,025(0,885)$ & $0,091(0,605)$ \\
\hline $\begin{array}{l}\text { V.14 } \\
\text { (R) }\end{array}$ & Coeficiente & $0,472 * *(0,003)$ & $0,091(0,597)$ & $0,012(0,947)$ \\
\hline V.15 & Coeficiente & $-0,165(0,322)$ & $-0,142(0,409)$ & $-0,053(0,762)$ \\
\hline V.16 & Coeficiente & $-0,088(0,601)$ & $-0,155(0,366)$ & $-0,256(0,138)$ \\
\hline $\begin{array}{l}\text { V.17 } \\
\text { (R) }\end{array}$ & Coeficiente & $0,351 *(0,031)$ & $0,083(0,629)$ & $-0,031(0,862)$ \\
\hline V.18 & Coeficiente & $-0,165(0,322)$ & $-0,251(0,140)$ & $0,005(0,978)$ \\
\hline
\end{tabular}

*Correlação é significativa ao nível de 0,05 . **Correlação é significativa ao nível de 0,01.

Observou-se que a correlação existente entre o Tempo de Empresa e os itens V.1, V2, e V3 são significativos e negativos. Assim, quanto maior o tempo de empresa, maior é o nível de concordância de que (V.1) administradores e gerentes concordam que a habilidade para a aprendizagem desta empresa é a chave para a vantagem competitiva; (V.2) os valores básicos desta empresa incluem a aprendizagem como chave para a melhoria; e (V.3) o senso nesta empresa é que a aprendizagem dos funcionários é um investimento, e não uma despesa. 
Também se observa correlação positiva e significativa entre a Idade dos respondentes e os itens V.14 e V.17. Assim, pode-se afirmar que quanto mais velhos os dirigentes, maior é a discordância de que (V.14) os administradores e gerentes da empresa não querem que a sua "visão de mundo" seja questionada; e que (V.17) uma ênfase na inovação constante não é uma parte de nossa cultura corporativa.

Finalmente verifica-se que existe uma correlação negativa e significativa entre o Tempo de Cargo dos participantes da pesquisa e suas percepções com relação aos itens V.5 e V.12. Assim, quanto mais tempo de cargo os respondentes tendem a ter, maior o seu grau de concordância com a afirmação que diz que (V.5) a cultura da empresa é aquela que não faz da aprendizagem de nossos empregados uma prioridade e com a afirmação que diz que (V.12) a equipe não tem uma visão bem definida para toda a empresa.

\section{Conclusões}

A empresa objeto de estudo desta investigação é considerada referência na área de sua atuação demonstrando um crescimento considerável nos últimos anos. Além disso, sua trajetória de expansão gera um interesse de pesquisa em busca de uma corroboração teórica observando suas práticas estratégias e gerenciais que possam explicar seu alto desempenho. Assim, este estudo buscou descrever a atual orientação para a aprendizagem da empresa em questão.

$\mathrm{O}$ instrumento de coleta de dados adotado demonstrou validade interna satisfatória para a avaliação do constructo do estudo. Ao analisar os resultados obtidos através da adoção de escala proposta por Sinkula, Baker, e Noordewier (1997) pode-se perceber que existem algumas questões que merecem maior atenção. Observou-se um alto grau de discordância no que diz respeito à existência de um consenso geral da visão de empresa disseminado em todos os níveis, funções e departamentos. Outra questão que merece atenção é o comprometimento dos funcionários com os objetivos da empresa, sendo que os mesmos não se vêem parceiros no mapeamento das direções da empresa. Além disso, outro aspecto que merece atenção é quanto à visão bem definida da empresa, onde através dos resultados obtidos pode-se perceber que os colaboradores não possuem essa visão. Mas de modo global, a empresa apresenta uma boa orientação para a aprendizagem na percepção de seus gestores e administradores.

Ao confrontar as percepções dos homens com as das mulheres da empresa quanto aos itens da escala de avaliação da Orientação para a Aprendizagem verificou-se algumas diferenças significativas. Com isso pode-se afirmar com relação atual da empresa que as mulheres do nível estratégico da empresa não compartilham da mesma percepção dos homens de que exista um senso comum a respeito do direcionamento do negócio e do compartilhamento de visão de negócio existente entre os níveis organizacionais da empresa.

Também se constatou que quanto maior o tempo de empresa, maior é o nível de percepção de que os investimentos em aprendizagem na empresa são essenciais para o sucesso. Isso se verifica como altamente positivo. Entretanto observou-se também que quanto mais tempo de cargo os respondentes tendem a ter, maior é a percepção de que a cultura da empresa é aquela que não faz da aprendizagem dos empregados uma prioridade e de a equipe te trabalho não tem uma visão bem definida para toda a empresa. Assim, observa-se que o tempo de cargo tende a elevar a visão de que a 
cultura e a visão do negócio não estão direcionadas às práticas orientadas para a aprendizagem.

Logicamente, por esse estudo se tratar de um estudo de caso onde o objetivo é efetuar um diagnóstico da empresa estudada, suas conclusões não podem ser generalizadas a outros casos, constatando-se este fato como sendo a maior limitação do estudo. Entretanto sugere-se a condução de estudos adicionais a respeito desta temática com vistas a identificar diferenças de percepção por parte dos tomadores de decisão de diferentes níveis organizacionais assim como de diferentes áreas funcionais. Assim, estudos dedicados a relacionar os mapas mentais (SENGE, 1990) e os estilos de aprendizagem vigentes em diferentes níveis organizacionais (ARGYRIS e SCHON, 1978) podem contribuir significativamente para a consolidação deste campo de estudos.

\section{Referências bibliográficas}

ARGYRIS, C.; SCHON, Donald A. Organizational Learning: A theory of action perspective. Reading, MA: Addison-Wesley, 1978.

BABBIE, E. Métodos de pesquisa de survey. Belo Horizonte: Ed. UFMG, 1999.

BARNEY, J. Firm resources and sustained competitive advantage. Journal of Management. v. 17, p. 99-120, 1991.

BETTIS, R. A.; PRAHALAD, C. K. The dominant logic: Retrospective and extension. Strategic Management Journal. V. 16, p. 5-14, 1995.

BRESCIANI, F. E. Processo de criação organizacional e processo de autoorganização. Ciência da Informação. vol.28 n.1 Brasília Jan. 1999.

Disponível em <http://www.scielo.br>. Acesso em: 20 de março de 2010.
BUENO, G. S.; BENEVIDES, Marcus. V.; ALBIERO, M. B.; VAZ, S. R. Gestão Estratégica do Conhecimento. Revista da FAE, Curitiba, v.7, n.1, p.89-102, jan./jun. 2004.

CRONBACH L. J. Coefficient alpha and the internal structure of tests. Psychometrika. V. 16, p. 297-334, 1951.

DE GEUS, A. P. Planning as Learning? Harvard Business Review. v. 66, p. 7074, 1988.

DICKSON, P. R. The static and dynamic mechanics of competition: A comment on Hunt and Morgan's comparative advantage theory. Journal of Marketing. v. 60, p. 102-106, 1996.

DOUGHERTY, D. Interpretive barriers to successful product innovation. Marketing Science Institute. Report No. 89-114. Cambridge: MA, 1989.

DRUCKER, P. F. Administrando para o futuro: os anos 90 e a virada do século. São Paulo : Atlas, 1992

EBOLI, M. Educação corporativa no brasil: Mitos e verdades. São Paulo: Editora Gente, 2004.

FIALHO, F. A. P. Ciências da cognição. Florianópolis : Insular, 2001 p. 263.

FLEURY, M. T., OLIVEIRA JR., Moacir. Gestão estratégica do conhecimento. São Paulo: Editora Atlas, 2001.

GARVIN, D. A. Building a learning organization. Harvard Business Review. v. 71, p. 78-91, 1993.

HOWELL, W. C.; COOKE, N. J. Training the human information processor: A look at cognitive models. In I. Goldstein (Ed.), Training and Development in Work Organizations: Frontier Series of Industrial and Organizational Psychology, New York: Jossey Bass, v. 3, p. 121-182, 1989. 
KIM, D. The link between individual and organizational learning. Sloan

Management Review. v. 35, n. 1, p. 3750, Fall, 1993.

KOLB, D. A. Experiential learning: experience as the source of learning and development. New Jersey: Prentice Hall, 1984.

MURRAY, B. A. Revolução total dos processos: estratégias para maximizar o valor do cliente. São Paulo: Nobel, 1996.

NARVER, J. C.; SLATER, S. F. Market orientation and the learning organization. Journal of Marketing. v. 59, p. 63-74, 1995.

NARVER, J. C.; SLATER, S. F. The effect of marketing orientation on business profitability. Journal of Marketing. v. 54, n. 4, p. 20-35, Out 1990.

NONAKA, I.; TAKEUCHI, H. Criação de conhecimento na empresa: como as empresas japonesas geram a dinâmica da inovação. Rio de Janeiro: Campus, 1997.

NYSTROM, P. C.; STARBUCK, W. To Avoid Organizational Crises, Unlearn. Organizational Dynamics. v. 13, p. 5365, 1984.

QUINN, J. B.; BARUCH, J. J.; ZIEN, K. A. Innovation explosion: using intellect and software to revolutionize growth strategies. New York: Free Press, 1997.

SENGE, P. M. A quinta disciplina: arte, teoria e prática da organização de aprendizagem. São Paulo: Best Seller, 1990.
SHAW, R. B.; PERKINS, D. N. T. Teaching Organizations to Learn. Organization Development Journal. v. 9, p. 1-12, 1991.

SIMON, H. A. Bounded rationality and organizational learning. Organization Science. v. 2, n. 1, p. 125-134, 1991.

SINKULA, J. M. Market information processing and organizational learning. Journal of Marketing. v. 58, p. 35-45, 1994.

SINKULA, J. M.; BAKER, William; NOORDEWIER, Thomas G. A framework for market-based organizational learning: Linking values, knowledge and behavior. Journal of the Academy of Marketing Science. V.25 (Fall). p. 305-318, 1997.

THOMKE, S.; REINERTSEN, D. Agile product development: managing development flexibility in uncertain environments. California Management Review, v. 41, n. 1, p. 8-30, Fall 1998.

TOBIN, Daniel R. Reeducating the corporation: Foundations for the learning organization. Essex Junction, VT: Oliver Wright, 1993.

WILLIAMSON, O. E. The economic institutions of capitalism: firms, markets, relational contracting. New York: The Free Press, 1985.

YIN, R. Estudo de caso: planejamento e métodos. 2. ed. Porto Alegre : Bookman, 2001. 